\title{
Local Television Political Advertising and the Manufacturing of Political Reality
}

\author{
Danilo Yanich ${ }^{1}$
}

(C) Springer Science+Business Media, LLC, part of Springer Nature 2020

\begin{abstract}
With so much media attention on the presidential campaign, how do voters learn about candidates and elections for other offices? On local TV news, political ads create the reality of local races - a reality that is not meant to inform voters but to persuade them. Voters are left to their own devices to fill in the space between what the ads say — the bought reality — and what political stories used to cover.
\end{abstract}

Keywords Political ads $\cdot$ Local television $\cdot$ Campaign finance $\cdot$ Political communication $\cdot$ Down ballot campaigns $\cdot$ Presidential campaign

In the 2016 election issue of SOCIETY, Robin Kolodny offered an insightful look into the possibility that Donald Trump could run a presidential campaign based on personality and less on money (Kolodny 2016). From the standpoint of political ads, she was on to something. In that campaign, Hillary Clinton (and her supporters) accounted for $75 \%$ of the political ads that appeared on broadcast television, while Trump accounted for only $25 \%$. Under normal circumstances, that would have produced a Clinton win-more ads, more votes.

But Trump had a trump card. It was the mainstream media. While Clinton had to pay for coverage, Trump got it for free. It was worth $\$ 5$ billion (Stewart 2016). Let's put that into perspective. In total, combining candidate committee and outside money, the Clinton campaign raised about $\$ 770$ million; Trump came in at $\$ 498$ million (Center for Responsive Politics 2017). That means that Trump's free coverage, or "earned media," was worth 6.5 times what Clinton raised and a whopping 10 times his own total.

Trump's tweets were irresistible to the television networks as he made one over-the-top statement after another, beginning with his characterization of Mexican immigrants when he announced his candidacy in June 2015. There were others. On October 19, 2016, three weeks before the election, Fox

Danilo Yanich

dyanich@udel.edu

1 Biden School of Public Policy and Administration at the University of Delaware, 111 Academy St, Newark, DE 19716, USA
News journalist Chris Wallace asked him if he would abide by the outcome of the election. He dodged the question. His answer the next day was ominous, announcing that he would do so "only if I win".

Broadcast television knew a reality TV star when it saw one. Its coverage of the campaign was laid bare in the comment of then-CBS president Les Moonves, who characterized the campaign as a "circus" that "may not be good for America, but it's damn good for CBS". He continued, "Sorry, it's a terrible thing to say. But, bring it on, Donald. Keep going" (Bond 2016). It was not only the sheer volume of the coverage, it was also its prominence. Trump's tweets in reaction to an opponent's statement were often covered before the statement. He suffered no negative consequences from his tweets - comments that would have been disqualifying in previous campaigns. Quite the opposite occurred: as he doubled down on his claims, he garnered the "love" that Kolodny predicted that did not accrue to any other candidate, especially Clinton.

However, if we look at the down-ballot races - the races for the House of Representatives and Senate - the 2016 campaign looked very much like previous elections. Political ads, not tweets, carried the messages of candidates because the vast majority of them did not enjoy the name recognition and celebrity of the presidential contenders. As a result, local television stations inundated citizens with political ads that often proclaimed mutually exclusive visions of reality. Specifically, of the 4.29 million ads that aired on broadcast television (not cable) in the 2015-2016 election cycle, only 
about 1 million targeted the presidential campaign. The remaining ads targeted down-ballot races, including 926,426 ads for Senate races (at a cost of $\$ 655$ million), 621,556 for House candidates (at a cost of $\$ 335$ million), 463,683 for governor races, and about 1.25 million ads for state attorney general, state representative, and mayoral races (Fowler et al. 2016). In other words, more than three-fourths of the political ads that we saw during a white-hot presidential campaign were directed at races that were not for the presidency. More importantly, we did not even recognize that imbalance.

To be sure, the presidential race had enough media coverage - broadcast television, cable news, social media, and talk radio - to make it seem that there were no other races being contested. It literally consumed all of the air in the room-precisely as Moonves had predicted. But that is the point. For the down-ballot races, political ads became critically important in a media environment in which they were the principal means for candidates to advance their messages. And they used television news to do that.

\section{Political Ads on Local Television News}

About half of all political ads for the presidential and downballot races were aired on local newscasts - that was about twice as many as were aired on all other news programs on networks combined, and twice as many as were aired on all entertainment and sports programs combined. That was higher than previous campaigns but consistent with the dominance of local television news for the placement of ads over time (Ridout et al. 2014).

In the research for my book, Buying Reality: Political Ads, Money, and Local Television News (on which this article is based), I examined ten media markets, nine of which were in battleground states. Campaigns made significant use of local newscasts for the airing of political ads. That makes intuitive sense-the stakes were high, races were competitive, voters needed to be persuaded, and political ads were the prime mechanism for that task (Dunaway et al. 2019).

In the 2016 election cycle, broadcast television captured almost $45 \%$ of the $\$ 9.8$ billion that was spent on political advertising - a decrease from almost $58 \%$ of $\$ 9.4$ billion in 2012. Both cable and digital advertising increased in that period, but they still only accounted for about $14 \%$ each. (Cassino 2017). That was different than the political spending patterns over the past six decades and the question is whether that signaled a blip in the pattern or a sea change in how political advertising will unfold in future campaigns. I think it is a bit of both. In the 2018 midterm elections, local television political ads reached an all-time high for a midterm cycle of over $\$ 3$ billion (Miller 2018). Everything we know about 2020 so far points to a record TV ad buy.

\section{Why Local TV News Matters}

The political advertisers who spent vast amounts of money on local television news did so because they recognized very important factors that make the medium particularly suited for political communication.

Audience Local television news commands the largest broadcast audience by far in a typical day. Its average daily audience is 18.1 million viewers (Matsa and Fedeli 2019). Compare that to the top three cable networks - CNN, Fox News, and MSNBC - which have a combined daily average of 1.9 million viewers (Grieco 2018).

Ubiquity There is a lot of local news. In fact, as of 2017, there are 1072 local television stations in the United States that air local newscasts for an average of almost $6 \mathrm{~h}$ per day on weekdays, an all-time high. On weekends, that number drops to an average of about 2 hours per day (Papper 2018). Put differently, on any weekday in the United States, the public has access to more than 6400 hours of local news broadcasts.

Primary Source of Local Information In 2011, a comprehensive report by the Federal Communications Commission (FCC) catalogued the shortcomings of local television news (Waldman 2011). But it also found that many stations genuinely strive to serve their communities with information that is important to citizens in the face of the reportorial gaps that have been left by the decline of newspapers. The report concludes that, given their local focus, "in many ways, local TV news is more important than ever" (Waldman 2011, p. 13). Local television news far outpaces other media as the primary source of local and regional news. Forty-four percent of the public got their news from local television; $12 \%$ turned to its closest competitor, newspapers; and 5\% said they get their news from social media (TVB and Keller Fay Group 2015).

Most Trusted News Source In general, trust in the media has declined. However, rather than not trusting any media, twothirds of the public indicates that it trusts only some media and not others. Most of the public (79\%) trusts the news it gets from their local television stations. A significant majority $(67 \%)$ say that they reference or repeat those news reports. That level of trust is consistent across Democrats $(82 \%)$ and Republicans (80\%) (TVB and Keller Fay Group 2015). Further, television is identified as the most trusted source of accurate political information for adults in the U.S. - at 61\%, it outperforms newspapers (47\%) and social media (31\%) (Video Advertising Bureau 2018).

Civic and Political Engagement Local television news is the most prominent news source for local voters and people who 
are civically engaged with their communities - those who vote, volunteer and connect with those around them. An analysis of data from the Pew Research Center provides evidence (Fig. 1). People who always vote are more likely to learn about their communities from local television news; indeed, $63 \%$ of people who vote regularly get their daily news from local television stations.

The political engagement of local TV viewers was not lost on campaign directors. David Plouffe, President Obama's campaign manager in 2008 and 2012, said that local television news was where the undecideds were, those voters who could still be persuaded: "What really mattered - and our research was clear as a bell on this-was the local news. True swing voters watched their local TV station and read their regional paper" (Plouffe 2009, p. 315). Further, "local television is the only source that draws a majority of both self-identified Republicans and Democrats and a near-majority of independents" (Ridout et al. 2014, p. 187).

In 2016, even as campaigns increased use of other media, broadcast television still had a three-to-one advantage in political advertising dollars because of its distinct advantages over cable as a prime vehicle for political ads. Smaller competitive markets are an advantage for local broadcast TV, because ads are more affordable to candidates and PACs and many congressional districts fall across multiple television markets, further benefitting the local TV option. Local broadcast news is key, because its audience still comprises the highest density of voters. Last but not least, local television stations can target audiences by program, time of day, and genre; local cable only targets by network, and the average cable interconnect reaches only about $44 \%$ of the television market. Local television reaches all of the market - that is, all of the voters (Poor 2014). As a result, local television newscasts were used for about half of all political ads, doubling the number of ads placed on other news programs such as cable, talk shows, etc.

\section{Method and Question}

My own research examined the political ads and political stories that appeared on local newscasts in the media markets of key battleground states across the presidential and downballot races during the 2016 election season.

The Campaign Period Election campaigns have become increasingly longer in the United States. Yet the time between Labor Day and Election Day is regarded as the most intense period of the campaign. The conventions are over, the slate is set, candidates are on nonstop schedules, political ads cover the airways - it's time to get busy. This is the time when campaign strategies, messages, and tactics will be on full display. As a result, I identified the period from September 5 (Labor Day) to November 7 (the day before the election) as the focus of the work. Further, this period was consistent with the lowest unit rate rule that governs the cost of political advertising to candidates (not PACs) in U.S. elections. Established in 1971 in the Federal Election Campaign Act (FECA), the rule states that the candidate must be charged the least expensive rate that the broadcaster offers for the requested airtime. The period in which that rule is in effect is sixty days prior to a general election and forty-five days prior to a primary election. The period from September 5 to November 7, 2016 was sixty-four days.

The Television Markets Access to the content of local newscasts was possible through a special arrangement with Internet Archive, a San Francisco-based nonprofit digital library. One of the archives that Internet Archive created focuses on local television news. Through the arrangement, Internet Archive provided streaming access to the complete local news broadcasts that formed the content database for the research. Our coding team accessed the broadcasts online and watched them exactly as they were broadcast over the air. We saw exactly
Fig. 1 Local news habits of those who always or sometimes vote (in percent). Source: Analysis of Pew Research Center data, "Civic Engagement Strongly Tied to Local News Habits," November 3, 2016 (Barthel, et al. 2016)

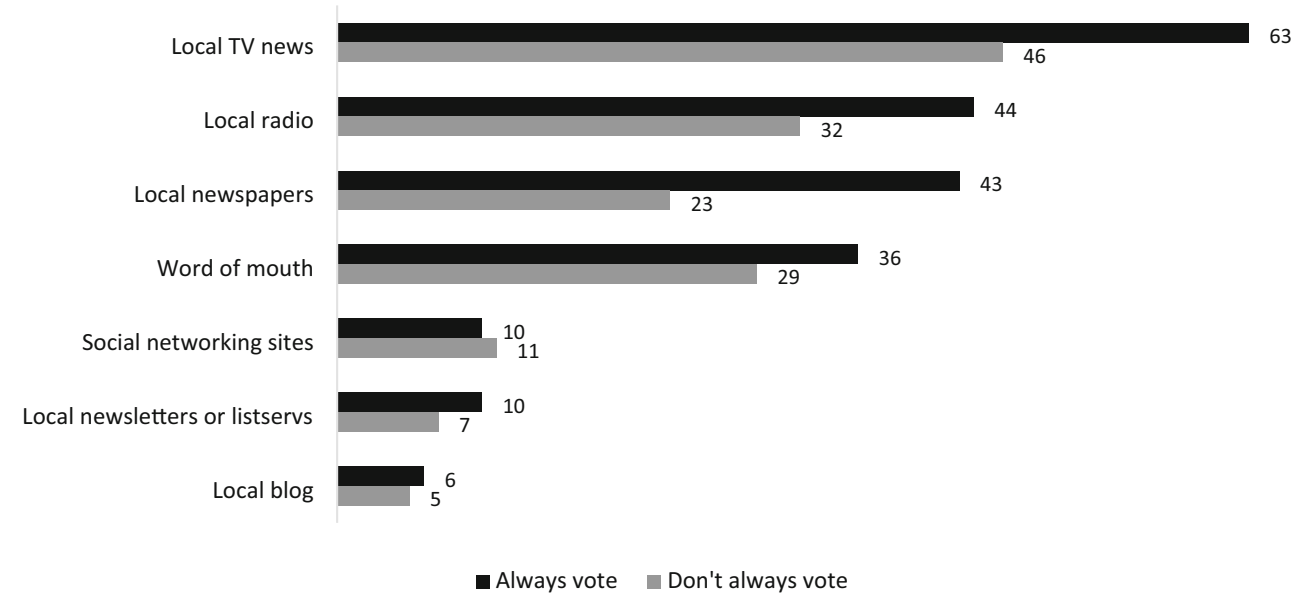


what the audiences saw in each of the markets for each of the newscasts.

There are 210 television markets in the United States, ranked by size as measured by the number of television households. For the 2016 presidential campaign, Internet Archive identified ten television markets across the country in which to capture the local newscasts of the stations throughout the campaign. Nine of the ten markets - with the exception of San Francisco-were in battleground states during the 2016 election (Mahtesian 2016).

The television markets that I studied were, in rank order of their size: Philadelphia (\#4), San Francisco (\#6), Tampa-St. Petersburg (\#11), Phoenix (\#12), Denver (\#17), ClevelandAkron (\#18), Raleigh-Durham (\#25), Milwaukee (\#35), Las Vegas (\#40), and Cedar Rapids-Waterloo (\#90). These rankings were based on Nielsen's National Television Household Universe Estimates for the 2016-2017 television season in which the number of television households was 118.4 million (Nielsen 2016). The combined markets in the research account for 15,347,230 (13\%) of U.S. television households and over forty-two million people (about $13 \%$ of the U.S. population).

The Television Stations The stations whose broadcasts were included comprised all of the network affiliated stations (ABC, CBS, Fox, and NBC) in the television markets that delivered a daily newscast to the viewers. There was one exception to that arrangement. Due to a technical difficulty, the CBS-affiliated station in Tampa (WTSP) was not included in the sample of stations. As a result, we coded the broadcast content of thirty-nine stations.

The Broadcasts The sample of broadcasts covered the period from Monday, September 5 through Monday, November 7 , 2016 (the day before the election) - nine weeks plus one day (November 7) for a total of sixty-four days. Each week (Monday through Sunday) and each market were treated as a separate entity. Therefore, I drew a random sample of sixteen broadcasts for each week in each television market. I applied the same 16-broadcast random sample approach to each market on November 7. This process assured an equal representation of broadcasts across markets and across the campaign period. This approach yielded a possible total of 1600 broadcasts as the basis for the content analysis (160 broadcasts each in 10 markets). However, the total number of broadcasts for the project was 1552 . That was due to a technical problem that Internet Archive experienced in the capture of broadcasts in Raleigh, North Carolina.

Political Ad Data The data for the political ads that were aired in the project markets were derived from Kantar Media, a research firm that monitors advertising, among other services. The database was specifically designed to meet the needs of the project. The Kantar data used the individual political ad as the unit of analysis. During the research period, 200,511 ads were presented on the stations in the markets that comprise the project. The variables for each ad that Kantar provided were: a link to the ad; the name of the sponsor; race to which the ad was addressed; the state and the television market in which the ad appeared; the station, network affiliation, the specific name of the program on which the ad appeared; the type of program (local television news, talk, news forum, slice of life, entertainment, news other, sports, other); the date and the exact time that the ad was aired; the length of the ad (in seconds); the daypart for Monday through Friday for which it specified precise time periods (early morning, daytime, early fringe, early news, prime access, prime time, late news, late fringe); the estimated cost of the ad; the type of ad (candidate, candidate and party, issue-election, party); party affiliation; the election for which the ad was aired (general, primary-Democrat, primary-Republican); the election level (federal, state); the specific issue addressed in the ad (where applicable); the race (U.S. president, U.S. House, U.S. Senate, governor); the tone of the ad (negative, positive, contrast). I used this data to construct variables in the database that were central to the analysis. The data formed the basis of the political ad analysis.

\section{Political Ads}

There were two aspects of political ads that were crucial to understanding how they were used across the presidential and down-ballot (DB) campaigns: where they appeared across the races and what they cost.

Quantity \& Money The most prominent finding that jumps out of the data is that the DB races got the lion's share of the money and the ads. In the sixty-four days during the campaign period, the local television stations in the ten markets showed their audiences 200,511 political ads_almost 3200 per day. But they were not evenly distributed between the presidential and DB races. Almost seven out of ten ads (69\%, or 138,662 ads) were directed at the DB races whereas just under onethird $(31 \%$, or 61,849 ads) referred to the presidential race (Fig. 2).

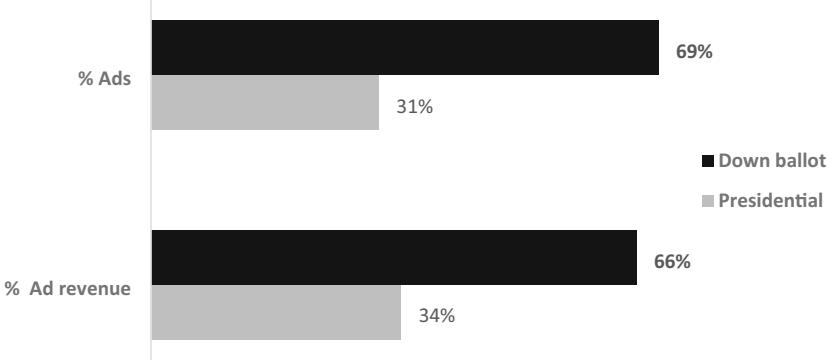

Fig. 2 Distribution of political ads and revenue by race 
That difference was also reflected in the money that was spent on the ads. The stations received a total of $\$ 220,501,650$ to air those ads during the campaign period. A very large proportion of that money-just under two-thirds, $\$ 145,234,490$ - went to ads for DB races; the remainder (34\%), $\$ 75,267,160$, paid for the airing of presidential ads (Fig. 2). In other words, the station revenue for DB ads almost doubled that for the presidential race. Both the number and cost of the ads represented a significant investment by political ad sponsors in the local television stations in these media markets. And remember, the volume of ads and the revenue that the stations derived from them only represents a 64- day period, albeit the most intense time of the campaign. The DB races were the overwhelming focus of political ads.

Ads by Market As the distribution of the total number of ads was uneven between the presidential and DB races, there was much variation across the ten markets regarding that same comparison. In all of the markets except Cleveland (shown in light gray in Fig. 3), there were more DB ads than presidential ads, and the differences between the races were significant. The overwhelming market leader in the number of ads that were aired for both races was Las Vegas (46,590 ads). But there were many more DB ads $(36,268)$ to presidential ads $(10,322)$. The ratio was 3.5:1. The audience in Philadelphia also saw a significant number of ads $(34,872)$ with a DB to presidential ratio of 2.9:1. The market in which the audience saw the fewest number of total ads was San Francisco (2338), but, again, there were many more DB ads (1587) to presidential ads (751) with a ratio of 2.1:1 (Fig. 3).

The larger point to be made is that in nine of the ten markets, there were more ads presented for the DB races than the presidential race. That difference was substantial except for Tampa, where the number of ads devoted to each race was about even (although there were still more DB ads). Among the other eight markets, DB ads at least doubled or more than tripled presidential ads. DB ads overwhelmingly carried the political advertising message in those markets.

Money by Market As we might expect, the volume of political ads in a market dictated the amount of revenue that the local television stations received during the campaign period. Las Vegas and Philadelphia saw the most political ads. The stations in Las Vegas aired over 46,500 political ads during the campaign period - the most of any market. As a result, its stations realized almost $\$ 55$ million in revenue, but the DB races garnered over $75 \%$ of that money, $\$ 41.5$ million, a ratio of 3:1 over the presidential race (Fig. 4). Philadelphia was another market in which political ad activity covered the airwaves. And although there were more total ads aired than in Las Vegas, the stations in the Philadelphia market enjoyed the highest revenue - almost $\$ 57$ million. That was because ad time on the Philadelphia stations, the fourth-largest market in the country, was more expensive than Las Vegas (number 40). But the revenue pattern mirrored Las Vegas. The DB races captured $71 \%$ of the money — over $\$ 40$ million to about $\$ 16.5$ million for the presidential race, a ratio of 2.5:1.

\section{Political Stories}

Television news programs deal with a finite resource - time. It is a zero-sum game. If some stories are in, then others are out. Therefore, the amount of time that a broadcast devotes to a particular story represents the importance it attaches to the topic. In order to examine this, I determined the amount of broadcast time that the stations devoted to types of stories. In rank order, soft news (human interest) occupied over one-

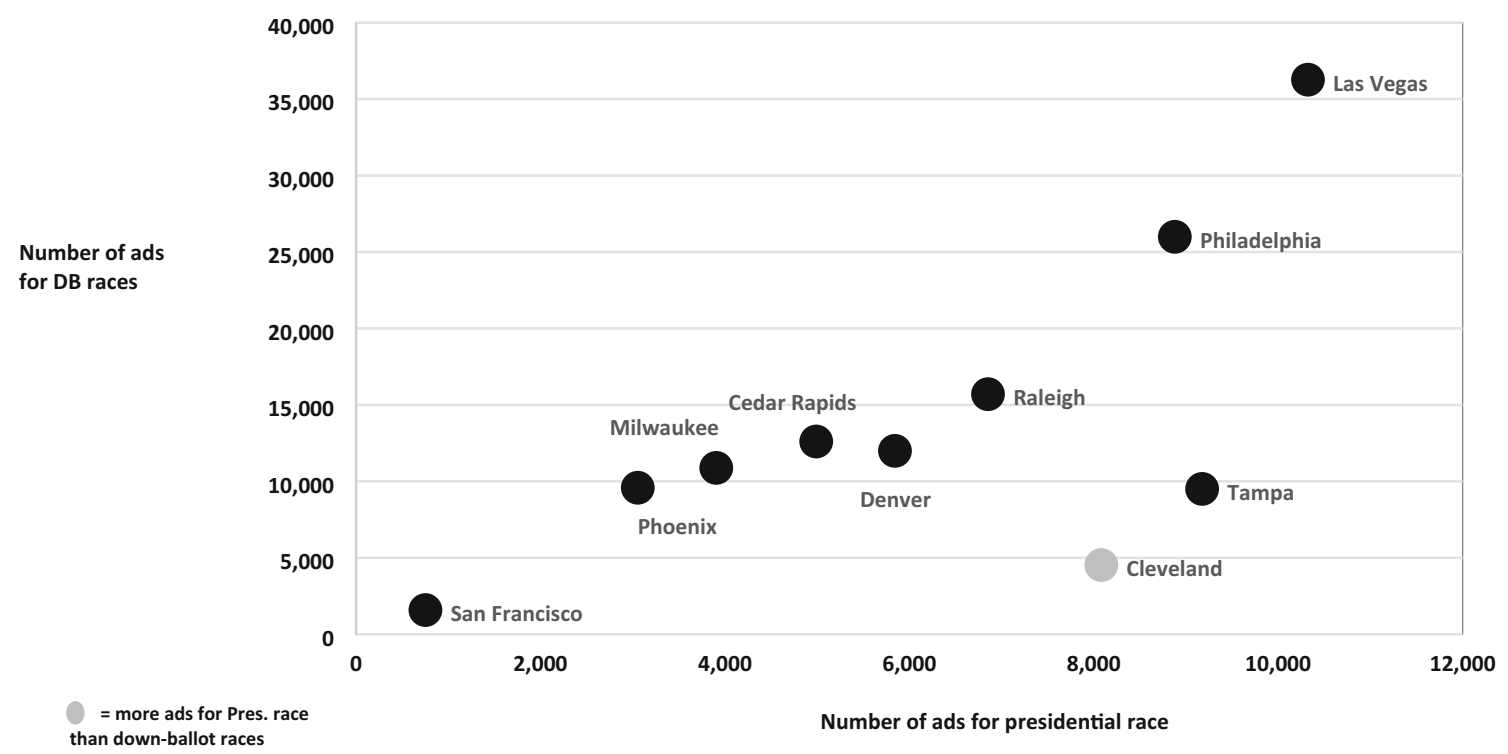

Fig. 3 Number of ads shown in down-ballot versus presidential races by market 


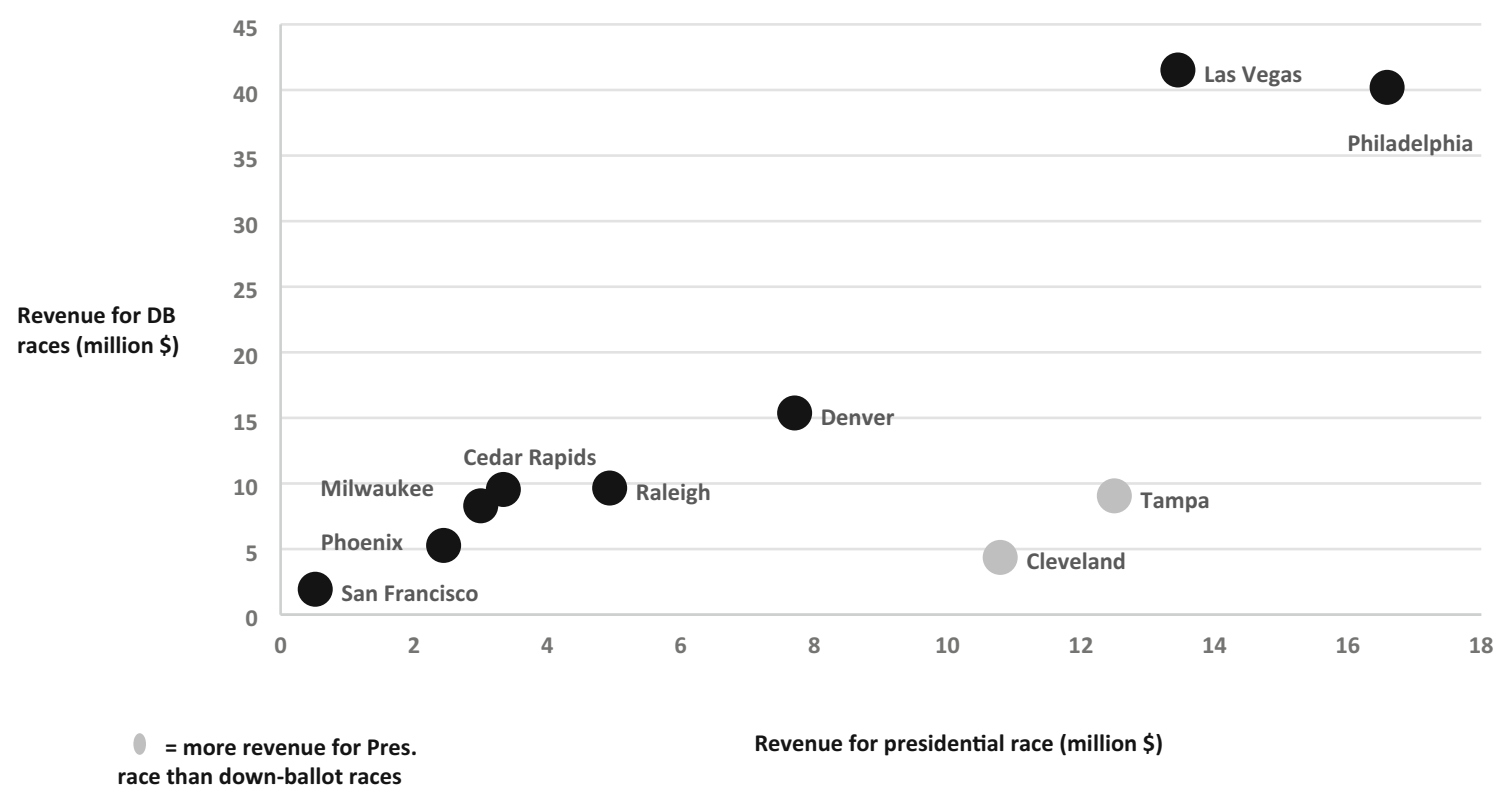

Fig. 4 Market revenue in down-ballot and presidential races

quarter of the time devoted to stories (27\%). They were followed by public issues other than crime, $(20 \%)$; political ads, (16\%); crime, (16\%); political stories, (13\%) and, last, fires/accidents, $(8 \%)$.

Let us put that into perspective. These broadcasts appeared in the last two months of uniquely intense presidential and down-ballot campaigns on stations in battleground states. Yet, even within that context, the amount of time that the stations devoted to campaign stories was next to last, half of what they used for soft news and less than they used for political ads. Further, political ads were only 30 seconds long and, in order to occupy more time than political stories (with a median length of 65 seconds), many more of them were broadcast.

How did the political ads, money and political stories play out across the presidential and down-ballot campaigns? The striking feature of the political stories across the races in all markets was that they were overwhelmingly directed toward the presidential race. Across all markets, almost nine out of ten $(87 \%)$ of the stories talked about presidential politics (or 3066 stories), leaving just $13 \%$ (428 stories) in the down-ballot column (Fig. 5). That is in stark contrast to the distribution of political ads and political ad money, in which the downballot races saw almost seven out of ten political ads and twothirds of the political ad revenue (see Fig. 2). There was clearly a difference between the emphases of the political ad buyers and the news selection calculus of the producers of the newscasts regarding which races to address.

\section{The Bottom Line}

Political ad money meant a great deal to the stations. To illustrate the point, let us use Las Vegas. It was the market in which the most political ads were shown on local TV news, but it represented the general trend. The four network-affiliated stations in Las Vegas aired more than 46,000 political ads, about 36,000 to the down-ballot campaigns and about 10,000 to the presidential. The stations received about $\$ 55$ million for that presentation over two months. In 2016 the Las Vegas stations collectively had $\$ 193$ million in total revenue - in other words, two months of political ads accounted for $28 \%$ of their total yearly revenue, a significant proportion. During those same two months, in 160 randomly selected broadcasts, the four stations in Las Vegas produced a combined total of 324 stories that were directed to the political campaigns. Political ads, for which the stations were paid handsomely, overwhelmed political stories. Even then, the political stories rarely mentioned, let alone examined, the claims of the ads. There is no future in biting the hand that feeds you.

\section{0}

What is driving these trends in political ads, news content and money? It is partly the result of the nation's politics, which are based on what Francis Lee described as "insecure majorities": holding the majority in major institutions of government is perpetually at risk, rendering compromise impossible (Lee 2016). Second, our political campaign finance system almost guarantees this version of politics. And third, the media system benefits greatly from both our politics and campaign finance system. Combined, they seem like the attributes of a perfect storm. They are even more profoundly at work in the 2020 campaign.

We already see it. Over $\$ 4.5$ billion will be spent on political advertising on television in the 2020 cycle. Kantar 
Fig. 5 Distribution of political ads, revenue, and political stories by race

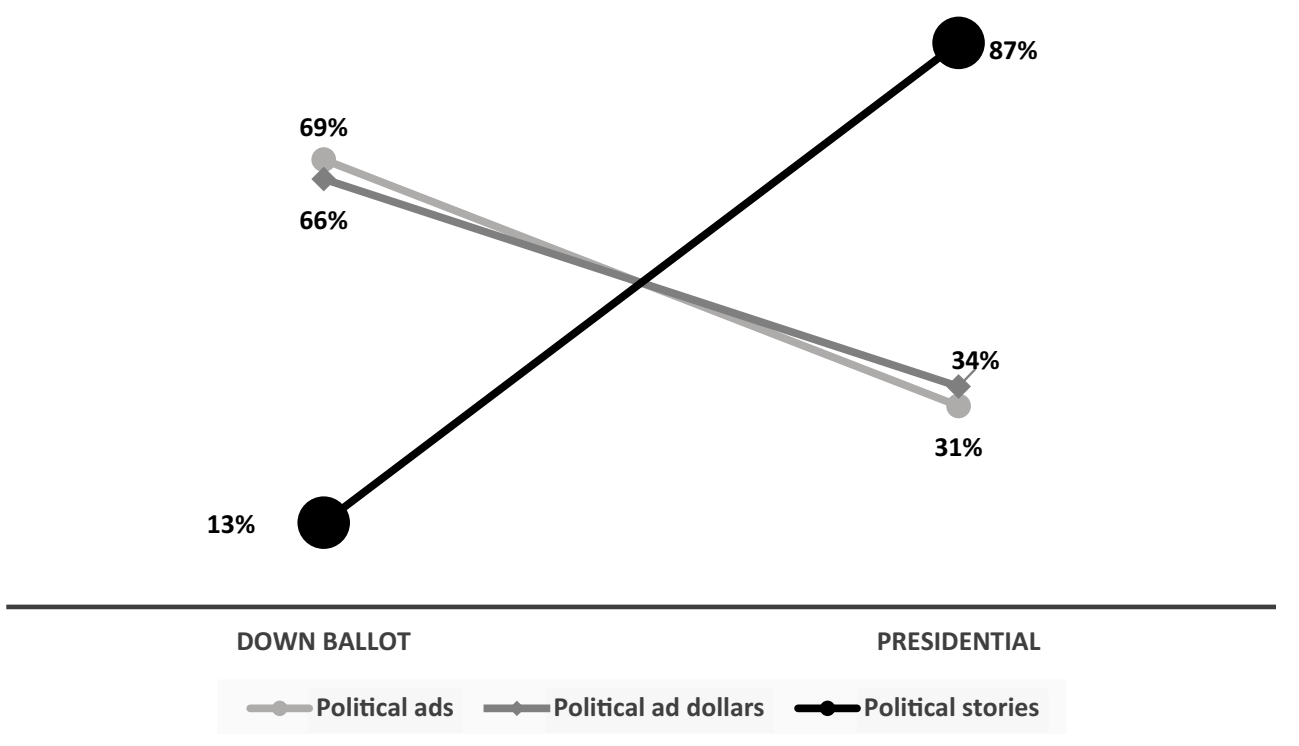

projects that total political ad spending will balloon to $\$ 7$ billion (Rubin 2020). Former New York City mayor Michael Bloomberg spent almost $\$ 1.1$ billion (Center for Responsive Politics 2020) in the 2020 election cycle in a failed bid for the Democratic presidential nomination, with about half (\$433 million) going to political ads on television; Tom Steyer, the businessman who also ran for the nomination while pushing for Trump's impeachment, spent over $\$ 150$ million (Bycoffe 2020).

I highlight Bloomberg and Steyer because the general media narrative is that they wasted their money. Why? Because they did not win the presidency or even get the nomination? Those criteria miss the essential point. Their millions of dollars of political advertising put them on the presidential debate stage. By that criterion, they succeeded spectacularly. Before the ads, neither had a shot. Yes, both failed miserably in that venue, but they were there.

Local television newscasts will be the epicenter of political ads in 2020 as they were in 2016. There are overwhelming reasons. First, local television news is virtually non-ideological. And, it reaches all of the voters in a jurisdiction, unlike cable or social media. Further, online advertising will not replace it. Twitter has banned political advertising. In late July 2020 as I write, Facebook, after months of intense criticism of its varied and contradictory positions, is considering banning political ads as well. COVID-19 has locked down the country and there are no more retail politics where candidates speak to crowds of enraptured supporters. As the pandemic threat increases, that will continue throughout the Fall except for when Trump may try to ignore it and plan rallies. He has already bought $\$ 150$ million in television advertising after Labor Day (Rubin 2020). Biden announced a \$280 million ad buy for the Fall..

As much as we thought that the 2016 campaign was an outlier in terms of its sheer shattering of previous norms, the
2020 contest will overwhelm it. The country is on edge and polarized. We have nationalized our politics, and votes for congressional candidates are seen in the context of what they mean for the insecure majorities in the House and Senate, not for what they might mean for local issues. We are tired of being cooped up in our homes by the pandemic. The protests surrounding George Floyd's murder (and others) have brought us to a reckoning that is long overdue. And Donald Trump has not changed his mind about abiding by the election results. On July 19, 2020, Fox News journalist Chris Wallace reiterated the question that he asked in 2016. Trump's response? "I have to see. Look, you - I have to see. No, I'm not going to just say yes. I'm not going to say no."

These are the conditions under which we must hold an election in November. And political advertising on television will still be a dominant form of political communication.

\section{Further Reading}

Bond, Paul. (2016). Leslie Moonves on Donald Trump: "It may not be good for America, but it's damn good for CBS". The Hollywood Reporter. Retrieved from www.thehollywoodreporter.com website: https://www.hollywoodreporter.com/news/leslie-moonves-donaldtrump-may-871464

Bycoffe, Aaron. (2020). Tracking Every Presidential Candidate's TV Ad Buys. Retrieved from www.projects.fivethirtyeight.com website: https://projects.fivethirtyeight.com/2020-campaign-ads/\# candidate $=$ michael-bloomberg

Cassino, Kip. (2017). The Final Analysis: what happened to political advertising in 2016 (and forever). Retrieved from Williamsburg, VA: https://www.borrellassociates.com/shop/the-final-analysispolitical-advertising-in-2016-detail

Center for Responsive Politics. (2017). 2016 Presidential Race. Retrieved from www.opensecrets.org website: https://www.opensecrets.org/ pres16 
Center for Responsive Politics. (2020). Expenditures. Retrieved from www.opensecrets.org website: https://www.opensecrets.org/ campaign-expenditures

Dunaway, Johanna, Searles, Kathleen, Fowler, Erika, \& Ridout, Travis. (2019). The effects of political advertising: assessing the impact of changing technologies, strategies and tactics. In P Napoli (Ed.), Mediated communication: Handbooks of communication science, Volume 7. Berlin: Mouton de Gruyter.

Fowler, Erika, Ridout, Travis, \& Franz, Michael. (2016). Political Advertising in 2016: The Presidential Election as Outlier? The Forum, 14(4), 445-469. https://doi.org/10.1515/for-2016-0040

Grieco, Elizabeth. (2018). Cable news fact sheet. Retrieved from Washington, DC: http://www.journalism.org/fact-sheet/cable-news/

Kolodny, Robin. (2016). The Presidential Nominating Process, Campaign Money, and Popular Love. SOCIETY, 53, 487-492. https://doi.org/10.1007/s12115-016-0054-0

Lee, Francis E. (2016). Insecure Majorities: Congress and the perpetual campaign. Chicago, IL: University of Chicago Press.

Mahtesian, Charlie. (2016). What are the swing states in 2016? Retrieved from www.politico.com website: https://www.politico.com/blogs/ swing-states-2016-election/2016/06/what-are-the-swing-states-in2016-list-224327

Matsa, Katerina Eva, \& Fedeli, S. (2019). Trends and Facts on Local News. Retrieved from www.journalism.org website: https://www. journalism.org/fact-sheet/local-tv-news/?utm_source=Pew+ Research+Center\&utm_campaign $=8$ b9f5278d3-EMAIL CAMPAIGN_2019_06_26_01_39\&utm_medium=email\&utm term $=03 \mathrm{e} 953 \mathrm{~b} 9 \mathrm{~b} 70-8 \mathrm{~b} 9 \mathrm{f} 52 \overline{7} 8 \mathrm{~d} 3-399352349$

Miller, Mark. (2018). Over \$3B Spent On Midterm Local TV Ads. Retrieved from www.tvnewscheck.com website: https:// tvnewscheck.com/article/225083/3b-spent-midterm-local-tv-ads/? utm_source $=$ Listrak\&utm_medium $=$ Email \&utm_term $=$ Over $\%$ $20 \% 243 \mathrm{~B} \% 20$ Spent $\% 20$ On $\% 20$ Midterm\%20Local\%20TV\% 20Ads\&utm_campaign=Over $\% 20 \% 243 \mathrm{~B} \% 20$ Spent $\% 200 n \%$ 20Midterm\% 20 Local\%20TV\%20Ads

Nielsen. (2016). Local television market universe estimates. Retrieved from New York, NY:

Papper, Bob. (2018). 2018 RTNDA/Hofstra University Newsroom Survey: Local News by the Numbers. Retrieved from Washington, D.C.: https://rtdna.org/uploads/files/2018\%20Local\%20News\% 20Research.pdf
Plouffe, David. (2009). The audacity to win: the inside story and lessons of Barck Obama's historic victory. London, England: Penguin.

Poor, Jack. (2014). Politics 2014: local market TV and the next political cycle. www.tvb.org

Ridout, Travis, Franz, Michael, \& Fowler, Erika. (2014). Advances in the Study of Political Advertising. Journal of Political Marketing, 13(3), 175-194. https://doi.org/10.1080/15377857.2014.929889

Rubin, Gabriel. (2020). How Many Political Ads Does $\$ 7$ Billion Buy? We're About to Find Out. Retrieved from www.kantarmedia.com website: https://www.kantarmedia.com/us/newsroom $/ \mathrm{km}$ inthenews/how-many-political-ads-does-7-billion-buy?utm campaign=CMAG\%20Digita1\%20Offering\%202020\&utm medium $=$ email\&_hsmi=91669118\&_hsenc $=$ p2 ANqtz98fihn7o6Xjv3bw6m0YZxvMLhHJvFKRU_0CB8Z0XdGETe E H L c A o a y j z X S g L V V 8 T c 82 N v Z 1 z 9 r 9 y z KK5eZApDES6L9Pw\&utm_content=91669118\&utm_source=hs email

Stewart, Emily. (2016). Donald Trump rode $\$ 5$ billion in free media to the White House. Retrieved from www.thestreet.com website: https:// www.thestreet.com/story/13896916/1/donald-trump-rode-5-billionin-free-media-to-the-white-house.html

TVB, \& Keller Fay Group. (2015). The American conversation study. (September 24, 2018). https://www.tvb.org/Default.aspx?TabID= 2203

Video Advertising Bureau. (2018). It's a matter of trust: media's influence on voters. Retrieved from New York City, NY: https://www. thevab.com/matter-of-trust/

Waldman, Steven. (2011). The information needs of communities. Retrieved from Washington, DC: https://transition.fcc.gov/osp/increport/The_Information_Needs_of_Communities.pdf

Publisher's Note Springer Nature remains neutral with regard to jurisdictional claims in published maps and institutional affiliations.

Danilo Yanich is a Professor in the Biden School of Public Policy and Administration at the University of Delaware. His new book, Buying Reality: Political Ads, Money, and Local Television News, was published by Fordham University Press earlier this year. 